\title{
Cuba: medio físico e infraestructura económica
}

\author{
Julio A. D íaz Vásquez \\ U niversidad de La H abana. Centro de Investigaciones de la Economia Internacional. \\ La H abana. Cuba
}

La H abana, noviembre-diciembre de 1995

\section{Resumen}

El trabajo compendia lo más relevante del medio geográfico de Cuba. 0 frece, en apretada síntesis, una caracterización de los recursos naturales, así como las formas que asume la explotación de la tierra y el desempeño del sector agropecuario de la Isla. D escribe el potencial y comportamiento de los sectores económicos incluyendo las principales ramas industriales del país. Relaciona el nivel alcanzado en el desarrollo de las actividades industriales, transporte y comunicaciones que apoyan el desenvolvimiento de la economía nacional. Varias tablas estadísticas muestran los datos que amplian el caudal informativo acerca de los medios e infraestructrua económica de que dispone Cuba

Palabras clave: sector agropecuario, complejo agroindustrial azucarero, concentración industrial.

\begin{abstract}
Cuba: Phisical environment and economic infrastructure
This piece of work sythesizes the most relevant aspects of $C$ uban geography and natural resources, as roell as the forms of land exploitation. It describes the role and behaviour of economic sectors and the development of industrial activities, transport and comunications. Statiscal data show the development of economic infrastructure of Cuba.
\end{abstract}

Key words: Cuban agriculture, Cuban sugar industry, industrial concentration in Cuba.

\section{Sumario}

Territorio y relieve

Recursos naturales

Tierra y potencial agrícola

El agro: salto socioeconómico
Sector agropecuario: agrícola y ganadería Complejo agroindustrial azucarero 0 tras ramas industriales Infraestructura económica 


\section{Territorio y relieve}

La República de Cuba, nombre oficial del país, no es sólo una isla, es en realidad un archipiélago formado por más de 1.600 cayos, islas e islotes. El archipiélago cubano posee una extensión territorial de $110.860 \mathrm{~km}^{2}$, de los cuales corresponden $104.945 \mathrm{~km}^{2}$ propiamente a la isla de Cuba. La cayería adyacente ocupa $5.915 \mathrm{~km}^{2}$, donde sobresale la isla de la Juventud (isla de Pinos) con $2.200 \mathrm{~km}^{2}$; disponiendo el resto de los cayos $3.715 \mathrm{~km}^{2}$. Las costas de Cuba se prolongan por $5.746 \mathrm{~km}^{2}$; distribuidos en 3.709 en la parte norte y 2.537 en la sur ${ }^{1}$, donde abundan hermosas playas, bahías e importantes poblaciones y excelentes puertos.

El archipiélago cubano está situado a la entrada del golfo de M éxico. Cuba está por el este a 77 km de H aití, separada por el estrecho de M aisí; al sur a $140 \mathrm{~km}$ de Jamaica, aislada por el estrecho de Colón; hacia el norte limita con los Estados U nidos de América, del cual la separan los $180 \mathrm{~km}$ del estrecho de la Florida; al oeste se encuentra a 210 km de M éxico, separada por el estrecho de Yucatán.

En el clima de Cuba predominan las condiciones tropicales marítimas; la temperatura promedio anual fluctúa alrededor de los $25,2^{\circ} \mathrm{C}^{2}$. Las precipitaciones medias oscilan cerca de los 1.375-1.450 mm, aunque en las zonas costeras y montañosas del país pueden tomar valores entre los 1.100 y los 2.000 $\mathrm{mm}$. En la I sla las cuatro estaciones naturales prácticamente se funden en dos. U na temporada de lluvia que se extiende entre mayo y octubre; la otra, de seca, que se prolonga desde noviembre hasta abril.

El relieve de Cuba está determinado, en gran medida, por el lugar que ocupa en el arco insular de las Antillas, al estar situada en la zona de interacción de las placas de América del $\mathrm{N}$ orte y del $\mathrm{C}_{\text {aribe }}^{3}$. En general, en la I sla predominan las Ilanuras y las sabanas que abarcan cerca del $70 \%$ del territorio nacional.

Las áreas de montañas sólo representan un $20 \%$. Se concentran en los sistemas montañosos de G uaniguanico en el occidente, en la provincia de Pinar del Río; el del Escambray o Guamaya en el centro, abarca las provincias de Villa Clara, C ienfuegos y Sancti Spiritus; la Sierra M aestra, en las provincias de Granma y Santiago de Cuba y, donde se alza la altitud cumbre del país, el Pico Real del Turquino con $1.974 \mathrm{~m}(\mathrm{~S} / \mathrm{N} / \mathrm{M})^{4}$ y el Grupo Sagua-Baracoa en el norte de la porción oriental, en las provincias de $\mathrm{H}$ olguín y G uantánamo ${ }^{5}$.

La hidrografía de la Isla está determinada por la posición y la configuración larga y estrecha, lo que condiciona las dos vertientes que la dividen; una norte y otra sur, que muestran las corrientes fluviales ${ }^{6}$. D e los más de 550 ríos

1. Anuario Estadístico de Cuba 1989. Comité Estatal de Estadísticas. La H abana, 1989, p. 20.

2. N uevo Atlas N acional de Cuba. Academia de Ciencias. La H abana, 1989, parte VI-VII.

3. Nuevo Atlas. O p. cit., parte IV.

4. Altura absoluta sobre el nivel del mar.

5. Anuario Estadístico. O p. cit., p. 23.

6. N uevo Atlas. O p. cit., parte VII. 
y arroyuelos que vierten sus aguas en ambas costas, algo más de un $80 \%$ ocupan superficies de cuencas que van desde los 40 a los $200 \mathrm{~km}^{2}$. El C auto, el mayor de los ríos, nace en la Sierra M aestra y tiene un recorrido de $370 \mathrm{~km}$.

Por su vegetación, Cuba se caracteriza por una alta diferenciación, dependiente en alto grado de la diversidad de la composición geológica y edáfica, dando origen a variadas formaciones vegetales. En el país pueden encontrarse ejemplares típicos de bosques tropicales, manglares, distintos tipos de arbustos, matorrales, plantas propias de costas rocosas y arenosas y herbazales acuáticos. También son comunes los restos de bosques, flora de sabanas, diferentes familias de plantas y cultivos tropicales, que agrupan algo más de 3.000 plantas superiores ${ }^{8}$.

\section{Recursos naturales}

Aunque la minería constituyó en Cuba la actividad inicial de los primeros colonizadores, la I sla no es rica ni abundante en recursos minerales. Las zonas de minerales metálicos conocidas más importantes se encuentran en la sierra M aestra, cerca de Santiago de Cuba; en el norte de H olguín, alrededor de las bahías de N ipe y M oa y en la región noroccidental de Pinar del Río. El 45\% del territorio nacional está ordenado en mapas geológicos a escala 1/50.000. Además, el $100 \%$ de la superficie posee levantamiento aerogeofísico con locaciones determinadas de yacimientos de polimetálicos, cobre, oro, plata y cromo con reservas calculadas y concluidas las investigaciones de tecnologías para su explotación? ${ }^{9}$.

Sin duda, la mayor riqueza minera del país está en los recursos lateríticos; mineral polimetálico con altos contenidos de níquel $(1,2 \%)$, cobalto $(0,1 \%)$, hierro $(40 \%)$ y aluminio. Los depósitos cubanos de níquel representan unos 800 millones de toneladas de mineral; el 45\% de las reservas mundiales; y rendimientos de níquel puro superior a los 19 millones de toneladas. Son explotables a cielo abierto en una franja de unos $200 \mathrm{~km}$ de este a oeste en la provincia de H olguín. También se conocen reservas de este mineral en la meseta de San Felipe, en Camagüey y en las alturas de Cajálbana, en Pinar del Río.

El cobre se explota en Cuba desde fines del primer tercio del siglo xvı. C asi agotados los yacimientos de El Cobre, en Santiago de Cuba y mina de $M$ atahambre, en el occidente de la Isla, las instalaciones existentes se encuentran en proceso de rehabilitación, y también se estudian otros puntos con posibilidades de aprovechamiento económico en esas regiones. I gualmente, se utilizan las piritas sulfurosas en la única planta de sulfometales del país instalada en la provincia de Pinar del Río. En proceso de ejecución está un complejo minero para explotar polimetálicos que contienen plomo y zinc, también en el norte de Pinar del Río.

7. Anuario Estadístico. 0 p. cit., p. 22.

8. Nuevo Atlas. 0 p. cit., parte $X$.

9. Revista Tips, abril de 1995, p. 24. 
D e otra parte, diversas asociaciones con capitales foráneos están introduciendo nuevas tecnologías para aprovechar recursos auríferos de minas empobrecidas o reservas de oro y plata descubiertas en diferentes lugares de la Isla. En tanto, los depósitos de magnetitas y cromo existentes en la parte oriental de la Isla están, en cantidades modestas, incorporadas a los rubros exportables, así como aportan materia prima para la producción de refractarios.

En lo relativo a los minerales no metálicos en 1989 (último anuario estadístico publicado), fueron extraídos del suelo cubano unos 30 millones de toneladas. Son abundantes las arcillas semirrefractarias y de cerámica roja en todo el territorio nacional, con usos intensivos en la producción de ladrillos, tubos, tejas, etc. En tanto los yacimientos arenosos se localizan en diversos puntos de la Isla; se emplean en la construcción y materiales de construcción, producción de vidrios y envases de cristal, fundiciones y otros destinos. Las reservas de arenas sílice en el occidente de Pinar del Río son de gran pureza con posibilidades de empleo en la industria electrónica.

D e alta calidad son las disponibilidades de rocas calizas que se reparten en enormes cantidades a lo largo y ancho del país. Encuentran amplia utilización en la industria de materiales de construcción, química y metalúrgica, en la producción de cal, además de emplearse en el mejoramiento de los suelos agrícolas. M ientras que la producción de cemento se ubica según la distribución territorial de los yacimientos de arcillas y carbonatos. El uso de la zeolita, cuyas reservas se extienden por toda la I sla, al canza cerca de las 100 mil toneladas anuales.

Por otra parte, Cuba dispone de amplias reservas de piedra, caolín y mármol. Estos dos últimos recursos se explotan por la industria de la cerámica y materiales de construcción en la isla de la Juventud. Asimismo, en la provincia de Ciego de Ávila existen importantes domos de sal gema con potencial utilizable en la produción de soda y sosa cáustica. Además, la Isla dispone de yacimientos de bentonitas, feldespato, dolomita, magnesita, fosforita y calizas fosfatadas, pero, en general, son pequeños o pobres ${ }^{10}$.

Asimismo, en la esfera de los hidrocarburos hasta el presente el país, en lo esencial, carece de fuentes propias para proveerse de combustibles fósiles. No existen recursos de carbón y las escasas disponibilidades conocidas de turbas, requieren de investigaciones complementarias para su aprovechamiento. Aunque en Cuba se extrajo por primera vez petróleo muy ligero y a la profundidad de 300 metros hace unos cien años, no es hasta los pasados años sesenta que la búsqueda y la explotación petrolera toma un importante auge.

Los avances logrados en el conocimiento geológico de la isla han permitido ubicar en una extensión de $120.000 \mathrm{~km}^{2}$ las zonas perspectivas de explotación, incluidas las áreas de la plataforma marina. $\mathrm{H}$ oy la capacidad disponible permite perforar unos 60 pozos cada año en un rango de 1.200 a $1.600 \mathrm{~m}$ de profundidad. Entre los 20 yacimientos descubiertos se encuentra el de Varadero,

10. Figueras, M iguel A. (1994). Aspectos estructurales de la economía de Cuba. La H abana: Editorial de Ciencias Sociales, p. 29. 
con reservas probadas de unos 1.100 millones de barriles. Las áreas de mayor interés están subdivididas en 33 bloques de los cuales en 18 bajo contrato de riesgo se realizan estudios geológicos y exploraciones por compañías de Francia, C anadá, Gran Bretaña, Suecia y Alemania.

La extracción de petróleo, de tipo pesado y alto contenido de azufre, se ha ido elevando gradualmente hasta alcanzar en 1995, en los casi 400 pozos en explotación, cerca de un millón 450 mil toneladas. La producción diaria de 35 mil barriles se elevará hasta los 38 mil en el año en curso, un $25 \%$ de esa cantidad se corresponde a lo aportado por la cooperación con firmas extranjeras. Un $80 \%$ del crudo se destina al consumo directo en varias termoeléctricas del país, lo que significa cerca del $35 \%$ del consumo de combustibles de la rama. El resto es utilizado en las fábricas de cemento y como materia prima para elaborar lubricantes y aceites industriales.

Por último, en el occidente y centro de la isla se explotan desde hace más de cien años pequeños yacimientos de rocas asfálticas, pero en general, sus calidades y potenciales son bajos. Se emplean fundamentalmente para pavimentar calles y carreteras.

\section{Tierra y potencial agrícola}

$\mathrm{H}$ istóricamente se reconoce que la feracidad de las tierras cultivables ha constituido el principal recurso natural de la Isla. La superficie potencial agrícola en 1989 abarcaba unos 6,8 millones de hectáreas que representaban aproximadamente el $62 \%$ de la tierra del país. Estando en cultivo 4,4 millones de hectáreas; o lo que es lo mismo, el 65\% de lo utilizable por la agricultura. Se estima que algo menos del $25 \%$ disponía de riego, esto es cerca de un millón de hectáreas. Los pastos naturales y tierras ociosas ocupaban 2,4 millones de hectáreas, es decir, el 35\% del área agrícola ${ }^{11}$.

El espacio no agrícola en 1989 ocupaba unos 4,2 millones de hectáreas, equivalentes al $38 \%$ de los suelos del país. Esta cifra se encuentra distribuida en 2,6 millones de hectáreas en áreas forestales; 609 miles de hectáreas no aptas para los cultivos agrícolas y silvicultura; 697 mil hectáreas destinadas al fondo poblacional constructivo y 330 mil hectáreas de espejos acuosos internos incluyendo presas y canales ${ }^{12}$.

En Cuba, excluyendo los pastos cultivados en 1989, era objeto de labor un equivalente a más del $30 \%$ del territorio nacional. D e considerarse los pastos el índice se eleva al $40 \%$. Antes de la revolución no se pasaba del $17 \%$ de los suel os agrícolas. Al duplicar el grado de utilización de las tierras cultivables, el país ha pasado a formar parte de los que se hallan entre los 10 primeros del mundo por este indicador.

Por otra parte, en función de las aptitudes para el riego, grado de erosión, profundidad de la capa vegetal, etc., los suelos cubanos pueden agruparse en las 
categorías de: mejor calidad (A), medios (B) y los mediocres (C). D e acuerdo con esta división convencional, la estructura aproximada daría al grupo $\mathrm{A}$ un $12 \%$, al B el $62 \%$, y al C el 26\% ${ }^{13}$. Las futuras incorporaciones de áreas cultivables sólo dispondrán del $7 \%$ del tipo A; Ios mayores recursos clasifican en el escalón B, concentradas en las provincias de Camagüey, Las Tunas, Pinar del Río, Granma, Villa Clara, Ciego de Ávila y Sancti Spiritus ${ }^{14}$.

No puede pasarse por al to que en los últimos 15 años los estudios de sue los realizados arrojaron que cerca del $15 \%$ de las tierras en explotación presentan índices altos de salinidad y grados de erosión que requieren ser atendidos. Los programas en ejecución para detener y revertir estas degradaciones, aunque en pequeña escala, presentan efectos al entadores al reincorporar decenas de hectáreas a la producción de viandas y hortalizas en la cuenca del Cauto, en Granma y valle de Caujeri, en Guantánamo.

Para fines del siglo XIX cerca del $50 \%$ de la superficie de la Isla se encontraba cubierta de bosques. El crecimiento de la producción de azúcar y cría de ganado llevaron a la reducción de las áreas forestales hasta el 15\% para mediados de los años cincuenta de esta centuria. La repoblación forestal tomó auge a partir de los años sesenta, al canzando las zonas boscosas en 1989 en las empre sas estatal es los 2,6 millones de hectáreas, desglosadas en 1,9 millones en bosques naturales, 350 mil en plantaciones y 250 mil hectáreas de tierras desforestadas ${ }^{15}$.

En su conjunto, al área forestal le corresponde el $60 \%$ de las tierras no agrícolas y cerca del $23 \%$ de la superficie potencial de empleo para la agricultura. En 1989 como promedio, hasta esa fecha, en los últimos 10 años se plantaban anualmente unas 43 mil hectáreas de bosques. Sin embargo, el país está lejos de llegar al $30 \%$ de zonas boscosas que recomiendan los organismos internacionales especializados. Los bosques y plantaciones forestal es ocupan un $17-19 \%$ del territorio nacional.

En lo concerniente a los recursos acuíferos, Cuba dispone de un potencial limitado, en lo fundamental, a causa de la geografía de la Isla, la cual origina que los ríos presenten corta longitud y pequeños caudales. Esto hace que el agua se convierta en un bien relativamente escaso. El caudal de agua disponible se ha estimado en 38 mil millones de $\mathrm{m}^{3}$ anuales. De ellos se consideran aprovechables unos 23 mil millones. El 25\% de esa cantidad puede extraerse del subsuelo y el resto de las corrientes y depósitos superficiales ${ }^{16}$.

Sin embargo, considerando un año normal de precipitaciones, en la actualidad, sólo son utilizables unos 10 mil millones de $\mathrm{m}^{3}$ de agua, menos del $50 \%$ del potencial aprovechable. D e este caudal, la agricultura consume el $75 \%$. EI país entre 1959 y 1989 concluyó unas 226 presas con capacidades de embal-

13. Instituto de Planificación Física, Programa Alimentario N acional 1986-1990. La H abana, enero de 1986.

14. Figueras, M iguel A. Aspectos estructurales Op. cit., p. 17-18.

15. Estimados a partir de: Anuario Estadístico. O p. cit., p. 185-186, 217.

16. Ver periódico Granma. La H abana, 6 de febrero de 1990. 
Tabla 1. Tierras agrícolas por tipos de propiedad (miles de hectáreas).

\begin{tabular}{llll}
\hline Conceptos & $\begin{array}{l}\text { Superficie } \\
\text { agrícola }\end{array}$ & $\begin{array}{l}\text { Superficie } \\
\text { cultivada }\end{array}$ & $\begin{array}{l}\% \\
\text { aprovechamiento }\end{array}$ \\
\hline CAI & 1.820 & 1.715 & 94 \\
Empresas estatales & 3.212 & 1.727 & 54 \\
CPA & 770 & 449 & 58 \\
Campesinos y CCS & 970 & 520 & 54 \\
Totales & 6.772 & 4.411 & 65 \\
\hline
\end{tabular}

Fuente: Anuario Estadístico. 0 p. cit., p. 184-185.

se cercanas a los 9 mil millones de $\mathrm{m}^{3}$, y unas 2 mil micropresas, que disponen de otros 900 millones de $\mathrm{m}^{3}$.

Excluyendo los desembolsos para instalaciones de riego, las inversiones en la esfera hidráulica sobrepasaron los 1.200 millones de pesos; aunque lo destinado a cuidados y mantenimientos ha quedado muy rezagado al no pasar del $1 \%$ de esa cifra. I gualmente, mucho peso en el bajo empleo de los recursos hídricos han tenido los retrasos y el alargamiento de los períodos constructivos de los embalses, así como los desfases en la terminación de las presas e instalaciones de canales, estaciones de bombeo y sistemas de riegos.

\section{El agro: salto socioeconómico}

A partir de 1959 la estructura de la propiedad agraria en Cuba sufrió cambios radicales. Las reformas agrarias de mayo de 1959 y octubre de 1963 dieron por resultado la transferencia al Estado de más del $70 \%$ del área agrícola del país. Las explotaciones agropecuarias tuvieron como centro la constitución de unidades estatales de diversa índole: complejos industriales azucareros (C AI), empresas y granjas arroceras, tabacaleras, cafetaleras, citrícolas, ganaderas, de cultivos varios, etc. M ientras que en las década de los setenta y, fundamentalmente en los ochenta, fue estimulada la unión de las tierras y recursos materiales de los pequeños propietarios agrícolas individuales para crear cooperativas de producción agropecuaria (CPA). Además, los campesinos privados se integraron en cooperativas de consumo y servicios (CCS), así como un número importante se mantuvo como productores dispersos.

Para finales de 1989 las CPA comprendían 1.353 unidades, ocupaban una superficie agrícola de 796,8 miles de hectáreas, más de 63.800 cooperativistas, una extensión media de 648 hectáreas y 47 miembros per cápita. Los campesinos individuales incluidos en un $80 \%$ en CCS constituían una masa superior a los 123.000 productores y disponían de cerca de un millón de hectáreas ${ }^{17}$. La tabla 1 muestra la distribución y el empleo de las áreas agropecuarias en dependencia de los tipos de propiedad. 
Tabla 2. Uso de la tierra por tipos de propiedad.

\begin{tabular}{llllll}
\hline & \multicolumn{1}{l}{$\mathbf{1 9 9 2}$} & & & $\mathbf{1 9 9 4}$ & \\
\cline { 2 - 3 } \cline { 5 - 6 } Conceptos & Miles ha & \% & & Miles ha & $\%$ \\
\hline Estatal & 5.098 & 75 & & 2.186 & 33 \\
N o estatal & 1.677 & 25 & & 4.500 & 67 \\
Distribuidas en: & & & & & \\
$\quad$ UBPC & 5.098 & 75 & & 2.826 & 42 \\
$\quad$ CAI y granjas & 690 & 10 & & 669 & 33 \\
CPA & 753 & 11 & & 773 & 10 \\
CCS & 234 & 4 & & 232 & 3 \\
$\quad$ Privado disperso & 6.775 & 100 & & 6.686 & 100 \\
Totales & & & & &
\end{tabular}

Fuente: Periódico Granma, 5 de diciembre de 1995.

Sin embargo, en octubre de 1993 se introdujeron mutaciones que modificaron radicalmente el modelo agrario conformado en los últimos treinta y cinco años. Fueron entregadas parte fundamental de las tierras estatales, en usufructo permanente gratuito a los colectivos obreros agropecuarios, así como se les traspasaron medios básicos valorados en 1.300 millones de pesos. Q uedando la estructura organizativo-productiva del sector agropecuario cubano a finales de 1995 conformada por cerca de 1.300 unidades básicas de producción cooperativa (U BPC) cañeras; al go más de 1.580 U BPC de cultivos varios; las empresas municipal es agropecuarias (EM A) y sus unidades básicas de producción (UBP) y otras empresas estatales en número de más de 400, las granjas integrales atendidas por el ejército juvenil del trabajo (EJT), que suman más de 120 unidades; unas 1.160 CPA; más de 2.700 C C S y unos 86.000 productores independientes.

Por último, se están entregando tierras a familias y particulares para fomentar producción exportable y el autoconsumo colectivo. Para el cultivo del café, el cacao, el tabaco y el coco las adjudicaciones alcanzaban a fines de 1995 más de 60 mil hectáreas. En el tabaco los contratos firmados comprenden más de 17 mil hectáreas, asignadas a 5.100 núcleos. Para el uso personal las parcelas de seis cordel es otorgadas a más de 165 mil usufructuarios sobrepasan las 41 mil hectáreas. La tabla 2 resume lo esencial de las variaciones habidas en el uso de la tierra por formas de propiedad al concluir 1994.

\section{Sector agropecuario: agrícola y ganadería}

Para 1989 en el Producto Social G lobal (PSG) el valor de la producción agropecuaria a precios corrientes representaba el $15 \%$. El sector ocupaba unos 877,4 miles de personas; equivalente al $23 \%$ de la fuerza de trabajo civil del país. D e ell 0s, 690,3 mil laboraban en unidades estatales, al go más de 64 mil eran cooperativistas y unos 123,1 mil campesinos individuales. En la esfera de 
Tabla 3. Valor de la producción ramal agropecuaria (a precios de 1981, millones de pesos).

\begin{tabular}{lrlrlrl}
\hline Concepto & $\mathbf{1 9 8 0}$ & $\%$ & $\mathbf{1 9 8 5}$ & $\%$ & $\mathbf{1 9 8 9}$ & $\%$ \\
\hline Sector agropecuario & 3.095 & 100 & 3.538 & 100 & 3.731 & 100 \\
Por ramas: & & & & & & \\
$\quad$ C añera & 972 & 31 & 1.001 & 28 & 1.093 & 29 \\
$\quad$ N o cañera & 744 & 24 & 933 & 26 & 987 & 26 \\
$\quad$ Ganadería & 1.352 & 44 & 1.568 & 44 & 1.612 & 43 \\
$\quad$ Servicios & 26 & 1 & 37 & 2 & 39 & 2 \\
\hline
\end{tabular}

Fuente: Anuario Estadístico. 0 p. cit., p. 91.

Cultivos Varios (no C añera) encontraban empleo unas 320 mil personas; de las cuales unas 218 mil trabajaban en granjas y empresas del Estado, unos 31 mil en cooperativas y aproximadamente 71 mil eran productores individuales $^{18}$.

D ebe señalarse que la calificación de la mano de obra resultaba significativa, al tener el $60 \%$ de los empleados del sector, nivel educacional de secundaria básica o mayor. U no de cada diez trabajadores poseía educación técnica; las ramas agropecuarias disponían de 22,1 mil graduados universitarios, o sea, uno por cada cuarenta empleados.

La evolución experimentada en la producción ramal agropecuaria muestra que su composición en la década de los años ochenta no sufrió cambios bruscos. La producción vegetal representó al rededor del $55 \%$ y la rama ganadera cerca del $45 \%$. Los servicios oscilaban en el 1-2\%. Dentro del ámbito vegetal la rama cañera mantuvo el mayor peso con aproximadamente el 30\% (ver la tabla 3). D e las áreas en cultivo donde se obtienen estas producciones, las exportables (caña de azúcar, tabaco, café) abarcaron cerca del $57 \%$ de la superficie. En tanto los alimentos para el consumo interno concentraron el restante $43 \%$; equival entes a 0,14 hectáreas por habitante.

En lo relativo a la estructura de la producción agropecuaria, teniendo en cuenta el régimen de propiedad de la tierra, hasta 1989, las empresas estatales aportaban el $78 \%$ de los valores producidos y los cooperativistas y campesinos privados el restante $22 \%$. N o obstante, por ramas estas proporciones variaban. Además, en determinados renglones en la esfera no cañera el sector no estatal tenía un peso importante o mayoritario. Así, entre otros, en raíces y tubérculos llegaba a más del 30\%; en hortalizas, cerca del $60 \%$; en tabaco, alrededor del $65 \%$; en la producción de café, el $60 \%$; en leche, el $20 \%$, así como en frutas, más del $50 \%$.

A su vez, los recursos productivos de la rama ganadera representaban cerca del $50 \%$ de los medios básicos del sector agropecuario. Éstos se concentraban en la producción de la cabaña bovina y las líneas productivas derivadas de las 
explotaciones porcinas, avícolas, ovino-caprino, équidos y la apicultura. En 1989 la ganadería empleaba unas 220 mil personas, con cerca de 203 mil laborando en las unidades estatales, unos 5,2 mil cooperativistas y alrededor de 12 mil productores individuales. La estructura de la producción de la rama presentaba una distribución aproximada del 30\% en carne vacuna, 30\% de leche, $14 \%$ de carne de aves, $12 \%$ de huevos, $12 \%$ de carne porcina y el $2 \%$ de otros renglones ${ }^{19}$ (miel, cera, carne ovino-caprina, conejos, etc.).

En la subrama vacuna encontraban ocupación unas 170 mil personas. D isponía de unos 3 millones de ha de pastos, de los cuales 1,1 millón de hectáreas correspondían a cultivados. El rebaño totalizaba 4,9 millones de cabezas; correspondiéndole al área no estatal 1,2 millones de animales. Estaban en explotación más de 2 mil vaquerías modernas con el ectricidad, ordeño mecánico, medios refrigerados y unas 370 mil vacas estabuladas como promedio. A estos recursos se agregaban la organización de un sistema de asistencia veterinaria nacional, incluyendo una industria de productos farmacéuticos veterinarios y servicios de inseminación artificial. Además, contaba con más de 5 mil técnicos medios y 3 mil de nivel superior para una relación de 22 trabajadores por graduado universitario y especializado.

Las efferas de la producción porcina y avícola en 1989 empleaba unas 38 mil personas; más de 10 mil en las instalaciones porcinas y 28 mil en las granjas avícolas. El número de cerdos alcanzaban el 1,3 millones de cabezas; y en las explotaciones avícolas, 2,8 millones de aves. Asimismo, los servicios veterinarios están muy desarrollados en estas dos subramas, así como resulta alta la calificación media de la fuerza de trabajo, existiendo en porcino 20 empleados por técnico con preparación universitaria y en la avicultura 50 obreros por graduado de nivel superior. En estas actividades las capacidades para el procesamiento de alimentos incluían más de 20 plantas de pienso líquido con producciones superiores a 1,1 millones de toneladas e instalaciones para procesar piensos sólidos con potencial superior a los 1,8 millones de toneladas.

Por otra parte, en 1989 en el resto de las producciones pecuarias trabajaban otras 12 mil personas. En su conjunto, en la ganadería había unas 900 mil cabezas ovino-caprino; unos 100 mil conejos como media anual y nacimientos superiores a los 600 mil animales promedio y más de 665 mil caballos y otros équidos. La apicultura disponía de 188 mil colmenas y 3.200 colmeneros estatales y privados; sien do Cuba a mediados de la década de los 80 el doceavo país apícola mundial y uno de los de más al to rendimiento por colmena.

Las tranformaciones operadas en el sector agropecuario pueden constatarse no sólo por los cambios socioeconómicos, sino también en el nivel de tecnificación que ostentaba este vital sector de la economía cubana. La tabla 4 resume algunas de las dotaciones de medios, a los que se suman el desarrollo de la mecanización lograda en labores agrícolas. Además, contaba con cerca de 30 plantas especializadas para reparar y reconstruir equipos, unos 400 talle-

19. Cuando no se indique la fuente, los datos proceden de varias publicaciones recopilados por el autor o procesados a partir del Anuario Estadístico. 0 p. cit. 
Tabla 4. Sector agropecuario. Indicadores seleccionados.

\begin{tabular}{llccc}
\hline Indicadores & Unidad & $\mathbf{1 9 7 5}$ & $\mathbf{1 9 8 0}$ & $\mathbf{1 9 8 9}$ \\
\hline Total de tractores & $\mathrm{mil}$ & 54 & 70 & 78,7 \\
Consumo de: & & & & \\
$\quad$ Fertilizantes & $\mathrm{mil} / \mathrm{t}$ & 959 & 1.574 & $1.869,3$ \\
$\quad$ Pesticidas & $\mathrm{mil} / \mathrm{t}$ & 7 & 11 & 15,8 \\
$\quad$ Herbicidas & $\mathrm{mil} / \mathrm{t}$ & 11,5 & 16 & 21,4 \\
$\quad$ Electricidad & $\mathrm{G} \mathrm{KW} / \mathrm{h}$ & 345,7 & 395,8 & 533 \\
Áreas de bajo riego & $\mathrm{mil} / \mathrm{ha}$ & 600 & 849 & 900 \\
\hline
\end{tabular}

Fuente: «Cuba: integración económica y especialización de la producción». La H abana: Editorial Pueblo y Educación. 1986, p. 71. Anuario Estadístico. O p. cit., p. 163-190.

res centrales en las empresas y más de 2 mil talleres de base y móviles para prestar asistencia a los equipos en el campo.

Sin embargo, aún cuando el índice de aprovechamiento del espacio agrícola resulta relativamente alto en C uba, así como los medios materiales que moviliza y las inversiones dirigidas al sector agropecuario entre 1961-1990 que, como promedio, llegó a cerca de 540 millones de pesos anuales, las importaciones tienen un peso significativo en el consumo de alimentos. Para inicios de los años noventa se tenía que más del $55 \%$ de las calorías, el $52 \%$ de las proteínas y más del $90 \%$ de las grasas contenidas en la dieta de la población se satifacía mediante las importaciones ${ }^{20}$.

Por último, en 1989 el sector silvícola constituía el 0,5\% del PSG y la mano de obra llegaba a 30,8 miles de personas. En tanto la demanda de madera bruta y elaborada superaba el millón de $\mathrm{m}^{3}$ anuales; cubriendo la producción nacional menos del $20 \%$ de la misma.

\section{Complejo agroindustrial azucarero}

La distribución sectorial del PSG de Cuba en 1989 evidencia que la industria, la agricultura y la construcción concentraban cerca del $80 \%$ del mismo. En tanto, dentro del sector industrial las actividades azucareras, alimenticias y bebidas y tabacos representaron más del $50 \%$ de la rama. Aunque debe advertirse que el peso del procesamiento de los alimentos y las bebidas está altamente influenciado por los precios de licores, tabacos y otros alimentos. Las tablas 5 y 6 muestran con creces estas tendencias.

D entro del sector industrial sobresale por el peso y las repercusiones en el conjunto de la economía del país, el complejo cañero-industrial productor de azúcar. En 1989 funcionaban 146 CAl y más de 80 empresas realizaban actividades complementarias o de apoyo a la industria azucarera. Asimismo, el influjo multisectorial de los CAl queda evidenciado por su peso relativo en 
Tabla 5. Producto Social G lobal por sectores (a precios corrientes, millones de pesos).

\begin{tabular}{lrr} 
Sectores & \multicolumn{1}{c}{ Valor } & \multicolumn{1}{c}{$\%$} \\
\hline Industria & 12.382 & 55 \\
Construcción & 2.439 & 9 \\
Agropecuario & 4.153 & 15 \\
Selvicultura & 124 & 1 \\
Transporte & 1.842 & 7 \\
Comunicaciones & 278 & 1 \\
Comercio & 5.249 & 11 \\
O tros & 186 & 1 \\
Totales & 26.653 & 100
\end{tabular}

Fuente: Anuario Estadístico. 0 p. cit., p. 88-93.

Tabla 6. Producción Bruta del Sector Industrial (a precios corrientes, millones de pesos).

\begin{tabular}{lrr} 
Ramas & Valor & $\%$ \\
\hline Energía eléctrica & 736 & 6 \\
Combustibles & 667 & 5 \\
M inería y metalurgia ferrosa & 181 & 1 \\
M inería y metalurgia no ferrosa & 225 & 2 \\
Construcción maquinaria no eléctrica & 744 & 6 \\
Electrotécnica y electrónica & 137 & 1 \\
Producciones metálicas & 170 & 1 \\
Química & 730 & 6 \\
Papel y celulosa & 141 & 1 \\
Gráfica & 141 & 1 \\
Forestal y elaboración de madera & 131 & 1 \\
M ateriales de construcción & 474 & 4 \\
Vidrio y cerámica & 61 & 1 \\
Textil & 296 & 3 \\
Confecciones & 180 & 1 \\
Cuero & 128 & 1 \\
Azucarera & 1.618 & 13 \\
Alimentaria & 2.276 & 18 \\
Pesquera & 261 & 2 \\
Bebidas y tabacos & 2.506 & 20 \\
Otras actividades & 541 & 5 \\
Hidroeconomía & 39 & 1 \\
Totales & 12.383 & 100
\end{tabular}

Fuente: Anuario Estadístico. 0 p. cit., p. 88-93. 
Tabla 7. CAl: instalaciones y equipos.

\section{Concepto}

Cantidades (unidades)

C entrales azucareros 156

Refinerías de azúcar

Terminales (embarque de azúcar a granel)

Tractores (todos los tipos)

40.000

Combinadas para la cosecha

4.200

Equipos de transporte (vagones, camiones y locomotoras)

Estaciones de limpieza (centros de acopio)

60.800

Linea de ferrocarril $(\mathrm{km})$

Fuente: $\mathrm{D}$ atos recopilados por el autor.

diferentes ramas: $12 \%$ en la construcción de maquinaria, $22 \%$ en la producción electrónica y electrotecnia, 5\% en la construcción y montaje, 17\% en la elaboración de proyectos nacionales, $18 \%$ en el transporte ferroviario y $45 \%$ en el automotor ${ }^{21}$. El azúcar representó en 1989 el 13\% del PSG , cerca del 80\% de las exportaciones del país y el $12 \%$ de los ocupados en el sector estatal. Entre 1961 y 1990 los CAI recibieron el 15\% de la corriente inversionista eje cutada; y en total representó unos 9 mil millones de pesos.

El complejo agroindustrial azucarero dispone del $27 \%$ de las tierras cultivables y emplea unos 450 mil trabajadores. En la rama cañera laboraban cerca de 330 mil personas, distribuidas en 270 mil en la esfera estatal, 28 mil cooperativistas, unos 40 mil campesinos individuales y en la industria unos $112 \mathrm{mil}$ obreros, técnicos y especialistas. El área sembrada de caña superaba el 1,9 millones de hectáreas, de las cuales 1.666 miles correspondían a los CAI, unas 235 mil a las CPA y cerca de 80 mil hectáreas a campesinos dispersos. La tabla 7 rela ciona el número de fábricas, instalaciones, equipos y otros medios que concentran los CAI.

Asimismo, las capacidades potenciales diarias de molida de las plantas productoras de azúcar alcanzan las 640 mil toneladas. En tanto la industria azucarera cubre algo más del $75 \%$ de sus necesidades de energía con la utilización del bagazo. La agricultura, el transporte y el consumo de electricidad en el proceso fabril por zafra demandan por término medio al rededor de 500-700 mil toneladas de combustibles derivados del petróleo.

Por otra parte, la utilización de los residuos del procesamiento industrial del azúcar y los desperdicios de la cosecha de la caña han ganado importancia industrial. Esta subrama representa algo menos del 3\% del valor de los medios básicos y cerca del $5 \%$ en el desempeño de la industria azucarera. Junto a las exportaciones tradicionales de mieles finales (melazas), alcohol y ron, se van 
incorporando otros rubros como la levadura torula, papel y madera artificial. Las posibilidades de mayor interés en el aprovechamiento de los desechos industriales y agrícolas de la caña se han implementado en la elaboración de fórmulas para alimento animal que, en buena medida, han paliado el déficit forrajero que padece la ganadería cubana (ver tabla 8).

Por último, el complejo cañero-industrial dispone de numerosas e importantes plantas mecánicas, así como instalaciones de proyectos y diseño agrupadas en empresas. Además, posee cuatro centros de investigaciones y, uno de ellos, vinculado directamente a la investigación-producción. La industria dispone de un elevado índice de calificación educacional de la fuerza de trabajo, al computar un técnico y especialista de nivel superior por cada cinco obreros empleados.

\section{0 tras ramas industriales}

Por sus recursos y disponibilidades de reservas productivas, el complejo minero-metalúrgico erigido alrededor de la explotación del níquel en el norte de la provincia de H olguin, constituye un eslabón de peso en el desempeño de la economía de Cuba. El mineral procesado en las plantas del país permite disponer de productos niquelíferos caracterizados por al canzar altos contenidos de níquel más cobalto. Entre los años 1973-1990 las inversiones programadas para el desarrollo y el aprovechamiento integral del níquel se aproximaron a los 3.500 millones de pesos. Para mediados de los años ochenta este proyecto estaba ejecutado en más del $45 \%$.

Así, entre otras direcciones, el programa contempló reconstruir y ampliar las capacidades de las dos instalaciones procesadoras de mineral existentes en 1959. La planta de M oa (Pedro Soto Alba), puesta en marcha en 1960, vio incrementadas sus capacidades desde las 18 hasta las 24 mil toneladas al año. La segunda, ubicada en $\mathrm{N}$ icaro (René Ramos Latour), inició la producción en

Tabla 8. CAl: plantas para tratar desechos.

\begin{tabular}{lc} 
Concepto & C antidades (unidades) \\
\hline D estilerías de alcohol & 16 \\
Fábricas de levadura torula & 11 \\
Fábricas de tableros de bagazo & 6 \\
Planta de pulpa y papel & 6 \\
Planta de dextrana & 1 \\
Planta de tratamiento de cachaza & 2 \\
Planta de miel-urea & 90 \\
Planta de miel-urea-bagacillo & 70 \\
Bagacillo predigerido & 50 \\
Plantas de sacharina & 20
\end{tabular}

Fuente: Recopilación del autor según varias publicaciones. 
1943; cerrada en fecha posterior a 1945 y reactivada en 1950 elevó sus potencialidades hasta las 22,5 mil toneladas por año.

También se proyectó la creación de otras capacidades productivas con la erección de dos nuevas plantas. La primera se levantó en Punta G orda (Ernesto Che Guevara), financiada por la U RSS (unos 780 millones de pesos), similar en tecnología productiva a la de $\mathrm{N}$ icaro. Terminada a mediados de los años ochenta, en la actualidad se superan los tropiezos tecnológicos presentados en su arrancada y asimilación de las capacidades de producción que, técnicamente, son de 30 mil toneladas al año. La segunda instalación, Las Camariocas, programada a construirse con participación de países miembros del CAM E, en proceso de ejecución, de igual tecnología a la Ramos Latour y de 30 mil toneladas de capacidad, se halla al 65\% de construcción. La primera línea productiva, de las tres de que consta el diseño de la planta, de 10 mil toneladas cada una, se encuentra al $75 \%$.

A su vez, para apoyar la esfera productiva se erigió un importante conjunto de obras de infraestructura. En primer orden un gran complejo mecánico levantado a un costo superior a los 110 millones de pesos; suministra más del $80 \%$ de los requerimientos de piezas de repuesto para el mantenimiento industrial de las plantas del complejo del níquel. Además, una empresa constructora que atiende los trabajos para ampliar y reconstruir las edificaciones fabriles y obras auxiliares. La parte científica incluyó un Instituto Superior M inerometalúrgico para la formación de técnicos e ingenieros de alta calificación; un Centro de Investigaciones de la Industria M inero-metalúrgica y el Centro de Investigaciones de las Lateritas del $\mathrm{N}$ orte de 0 riente.

El complejo del níquel cuenta en la actualidad con diseño de capacidades superiores a las 75 mil toneladas. En 1995 se inició la recuperación productiva de esta industria al procesarse 43,9 mil toneladas de níquel; que son exportables en su totalidad y aportan ingresos brutos en divisas superiores a los 200 millones de dólares.

D e otra parte, las ramas metalmecánicas y construcción de maquinaria disponen de un potencial superior a las 70 mil máquinas herramientas. Las capacidades productivas pueden localizarse en cinco regiones donde se concentran Ios núcleos mecánico-productivos principales del país. Sobresalen las zonas de H olguín-Las Tunas, con un complejo metalmecanico-metalúrgico integrado por plantas productoras de laminados, cosechadoras, equipos e implementos agrícolas, carretas y remolques de uso agropecuario, estructuras de acero, etc.; al que se agrega el importante combinado mecánico enclavado en el comple jo del níquel. Este conjunto de instalaciones fabriles representó inversiones cercanas a los 300 millones de pesos ${ }^{22}$.

22. D ebe añadirse que en el sector industrial unas ramas se crearon y otras se desarrollaron con la asistencia de los países miembros del CAM E y, en primer lugar, dela U RSS. Una exposición en detalle puede consultarse en: D ÍAZ VÁZQUEZ, Julio A. (1988). Cuba y el CAM E. La H abana: Editorial de Ciencias Sociales, p. 58-144. 
A su vez, las regiones de C amagüey y Villa Clara, vieron surgir en los pasados años potentes polos mecánicos abarcadores de una amplia gama de máquinas, equipos mecánicos, instrumentos eléctricos y medios electrónicos. En particular, fue estructurado un conjunto de plantas capaces de entregar el 60\% del equipamiento mecánico y tecnológico para los centrales azucareros. El centro de este complejo lo forman las plantas mecánicas y de calderas de Santa Clara y el combinado mecánico de Camagüey, que representaron desembolsos cercanos a los 400 millones de pesos. La instalación camagüeyana, equipada con varias baterías de máquina-herramientas programables significó inversiones por unos 170 millones de pesos.

En tanto, la región occidental cuenta con las concentraciones industriales de La H abana y Pinar del Río. D estacan las instalaciones para producir casi un millón de toneladas de acero, incluyendo unas 20 mil de acero inoxidable, 60 mil toneladas de refractarios, motores D iesel, partes y piezas para la industria automotriz, así como capacidades dedicadas a producir cables telefónicos, mobiliario metálico para hospitales y hoteles, equipos de electromedicina, una amplia variedad de objetos de acero inoxidable y aluminio, etc., en surtidos superiores a los 8 mil artículos. La creación de tal es potencialidades concentraron recursos por encima de los 600 millones de pesos.

La electrónica y la electrotecnia integran combinados y otras instal aciones, entre las que destacan las de televisores, radios, componentes electrónicos, circuitos integrados y semiconductores, así como las producciones de pizarras telefónicas, trimmers y planta piloto de silicio monocristalino. Unos 10 mil obreros calificados y especialistas laboraban en estas actividades. Las ramas reseñadas en su conjunto vinculan unas 150 empresas integradoras de diferentes unidades fabriles; la calificación se desarrolla en más de 10 centros de superación y 30 empresas mantienen programas asociados a institutos politécnicos. Además, disponen de una fuerza de trabajo de más de 72 mil personas con promedios de escolaridad de doceavo grado; de ellos, unos 24 mil son universitarios o técnicos; por cada tres trabajadores hay un graduado de nivel superior o calificación especializada23.

La rama química tiene como centro la industria de fertilizantes, abonos granulados y mezclados. La producción se realiza en las instalaciones de M atanzas, y los combinados de $N$ uevitas y $C$ ienfuegos, las cuales entregan urea, ácido nítrico, fertilizantes nitrogenados y nitrato de amonio, además de disponer de capacidades de elaboración de herbicidas superiores a las 5 mil toneladas. Al agregarse otras tres plantas productoras de abonos granulados y dos mezcladoras, las capacidades productivas ascienden en total a más de millón y medio de toneladas.

En la producción de papel las cinco plantas existentes en el país vieron ampliadas sus posibilidades productivas con la erección de dos fábricas de más de 80 mil toneladas de cartón y cartulina. A las que se sumó un gran combi- 
nado capaz de entregar 60 mil toneladas de papeles blancos y de escritura. Al mismo tiempo, se ejecutó un programa para modernizar las instalaciones de papel de diversos calibres y sanitarios y elevar sus capacidades en otras 50 mil toneladas. Asimismo, en la jabonería y detergentes las tres plantas existentes llevaron sus índices productivos hasta las 55 mil toneladas (tocador y lavar) y cerca de 60 mil en detergentes industriales y para el hogar, unas 15 mil toneladas de detergentes líquidos, así como 10 mil toneladas de crema dental24.

A su vez, en la producción y recape de neumáticos, las capacidades disponibles rozan las 800 mil unidades; en tanto las plantas productoras de oxígeno, nitrógeno líquido, argón y acetileno, en unos casos el evaron o abrieron nuevas capacidades e incorporaron a la economía nacional nuevos renglones, aunque no siempre satisfacen la demanda. D e otro lado, el aprovechamiento y la producción de las salinas del país se incrementó al subir su potencial por encima del medio millón de toneladas en sal para consumo humano, piensos, tenerías y otras necesidades industriales. También las líneas productivas de sosa cáustica, hipoclorito de sodio, cloro líquido y ácido clorhídrico superan las 100 mil toneladas anuales y unas 80 mil las de ácido sulfúrico.

La rama del vidrio remozó y rehabilitó las instalaciones en explotación para producir vidrios planos, frisando sus entregas anuales los $600 \mathrm{mil} \mathrm{m}^{2}$. Al tiempo que las capacidades de envases de vidrio en las dos principales plantas del país cubren las necesidades con la entrega de 550 millones de botellas, además de aportar partidas exportables.

La industria textil cuenta con combinados y fábricas en disposición de procesar anualmente unos 375 millones de $\mathrm{m}^{2}$ de tejidos planos; 65 millones de toneladas de hilazas; plantas para tejidos de punto que, en su conjunto, producen más de 50 millones de $\mathrm{m}^{2}$ de tejidos, suficientes para confeccionar 44 millones de prendas de vestir, así como capacidad instalada para entregar 14 millones de toallas al año. Las confecciones textiles están concentradas en 190 fábricas y talleres con capacidades anuales de 100 millones de prendas de vestir en dos turnos de trabajo.

En la rama del calzado y el cuero existen más de 100 fábricas y talleres con cerca de 16 mil operarios, incluidos tecnólogos, diseñadores y especialistas calificados, que elaboran las pieles, producen calzado y crean artículos de talabartería. En el calzado las capacidades instaladas en 65 plantas alcanzan los 17 millones de pares al año. Las instalaciones curtiembres tratan pieles bovinas, ovino-caprinas, equinas y especies exóticas, en el orden de los 2 millones de $\mathrm{m}^{2}$ y 600 toneladas de suela anuales. En talabartería el respaldo productivo recae en 24 fábricas talleres que elaboran objetos de piel natural y sintética de reconocida calidad.

La industria gráfica agrupa fábricas, talleres y combinados poligráficos que, de conjunto, operan capacidades productivas anuales ascendentes a 56 millones de revistas; 50 millones de libros y folletos; 20 millones de libretas escola- 
res; 318 millones de pliegos tipo 70 x $100 \mathrm{~cm}$ y 300 millones de formas continuas. M ientras que en la elaboración de madera las condiciones para la producción de muebles en series y exclusivos supera las 115 mil unidades al año. Agregándose, además, unas 650 mil unidades anuales de lámparas industriales, comerciales y decorativas.

Por otra parte, las ramas alimentaria y de bebidas y tabaco asimilaron entre 1965 y 1985 unos 900 millones de pesos en inversiones que permitieron reconstruir, ampliar, modernizar y explotar unas 365 fábricas e instalaciones. Sobresalen entre estos objetivos las plantas y combinados para el tratamiento de leche, producción de helados, yogurt, queso, mantequilla, etc. En la industria cárnica mataderos, empacadoras, frigoríficos, etc.; se remodelaron y construyeron panificadoras e instalaron nuevas capacidades para molinar trigo y procesar maíz, secaderos y molinos de arroz, etc. Las conservas de frutas y vegetales recibieron impulsos sustanciales con tres modernos combinados para el procesamiento industrial de los cítricos, así como más de 25 plantas para conservas varias, caramelos, glucosa, etc. En bebidas y tabaco se remodelaron cinco cervecerías y se erigieron dos nuevas plantas; 15 fábricas de refresco y aguas minerales y 30 plantas para hielo; un moderno combinado licorero de 30 millones de hectolitros y se modernizaron varios talleres y fábricas de tabaco.

En la pesca resulta decisiva la participación de la flota de altura, así como la presencia de las flotas del $\mathrm{C}$ aribe y de Plataforma. Cuenta la industria pesquera con un puerto especializado en $\mathrm{La} \mathrm{H}$ abana que dispone de 1.584 metros de muelles; 16 talleres y 3 diques flotantes para la reparación de buques de hasta 2.800 toneladas de desplazamiento; 3 frigoríficos de 25 mil toneladas de carga y una planta de hielo; 1.500 trabajadores y más de 200 profesionales al tamente calificados. Las capturas en los últimos años han estado al rededor de las 190 mil toneladas, de las cuales unas 30 mil provienen de la plataforma de la Isla. De esta cantidad unas 10 mil toneladas corresponden a langostas y camarones. D ebe señal arse que las aguas insulares están en el límite de sus potencial idades.

\section{Infraestructura económica}

Como soporte productivo, la infraestructura material de la economía cubana ha experimentado profundas transformaciones en los últimos treinta años. Así, las ramas eléctrica y de combustible representaron en 1989 el 5\% del PSG. EI petróleo y el bagazo cubrían más del $90 \%$ de las necesidades totales de combustibles. La energía eléctrica llegó a su máxima producción en 1989 con $15.240 \mathrm{G} \mathrm{W} / \mathrm{h}$; y correspondió a las plantas termoeléctricas el $98 \%$ de la electricidad generada. En tanto la potencia instalada era de $3.988 \mathrm{M} \mathrm{W}$, de los cuales $3.756 \mathrm{M} \mathrm{W}$ pertenecían a termoeléctricas; operando el servicio público nacional $2.968 \mathrm{M} \mathrm{W}$; y otras empresas (níquel, azúcar, etc.) disponían de 788 M W. En estaciones hidroeléctricas, turbinas de gas, plantas D iesel, etc. se explotaban $232 \mathrm{M} \mathrm{W}$.

El servicio electroenergético público genera cerca del $90 \%$ de la electricidad del país, además de poseer las plantas más eficientes. D ispone de nueve 
instalaciones con capacidades entre 120-600 M W; de ellas, cuatro se erigieron con tecnología socialista y otras usinas se modernizaron con turbogeneradores checos o soviéticos; cerca del $70 \%$ de las turbinas del sistema tienen esta procedencia. En 1992 la potencia instalada en el sector eléctrico nacional alcanzó $3.132 \mathrm{M} \mathrm{W}$; la generación bruta los $9.924 \mathrm{G} \mathrm{W}$; brindando servicios a 2.636.000 consumidores; el $85 \%$ de la población de la Isla. Al tiempo que la red de distribución, integrada en un circuito único, la formaban 2,5 miles de km de línea de $220 \mathrm{kV} ; 3,8$ miles de km de $110 \mathrm{kV}$ y 40,9 miles de $\mathrm{km}$ de $33 \mathrm{kV}$ y menores. El consumo específico de combustible era de 270 gramos por kW/h.

La rama de los combustibles comprende tres actividades: extracción, refinación y distribución. M ientras que las importaciones de petróleo y sus derivados históricamente cubrieron el 95\% de las necesidades del país, lo que está asociado a la baja contribución de la producción interna y las capacidades de refinación disponibles que, ni en calidad, surtido y cantidad satisfacen los requerimientos de la Isla. En 1988 las importaciones de petróleo crudo fueron de 8,5 millones de toneladas, el petróleo combustible 3.229 millones, las de D iesel (fuel-oil) 1.203, las de gasolina 96 mil y la producción nacional de sólo 717 mil toneladas. Las capacidades de corrida en las refinerías sumaban 8,2 millones de toneladas.

Todos los trabajos involucrados en la extracción, procesamiento y distribución de los combustibles están integrados en la corporación C uba-Petróleo. Esta entidad administra las tres refinerías en operaciones en la economía. La de La H abana, con capacidad de destilado del orden de los 4,6 millones de toneladas de crudo; la de Santiago de Cuba, de 3,6 millones de toneladas de procesamiento y una pequeña planta en la provincia de Sancti Spiritus (C abaiguán), que elabora crudo nacional destinado a materias primas para la producción de abonos complejos, grasas y aceites especiales.

Para superar el desbalance entre las necesidades de refinación de productos claros y las capacidades de corrida, se construyó en Cienfuegos una nueva planta que, en su diseño, comprendió dos líneas de elaboración de 3 millones de toneladas cada una. Valorada en 320 millones de pesos, financiada por la U RSS, está concluida la primera batería productiva y se busca asociación con capital extranjero para ponerla en marcha y concluirla. Además, la rama incluye un combinado de lubricantes en Santiago de Cuba para reciclar aceites usados, así como producir grasas y mezclar lubricantes en capacidades totales de unas 90 mil toneladas y costo cercano a los 60 millones de pesos.

La construcción y el montaje a mediados de los años ochenta daba empleo a más de 240 mil obreros; la rama concentraba unos 60 mil equipos, lo que significó inversiones superiores a 900 millones de pesos; y capacidades para reparaciones y mantenimeinto del parque disponible valorados en más de 60 millones de pesos. A su vez, la industria de materiales de la construcción y cerámica reúne unas 200 plantas y talleres; demandaron desembolsos por encima de los 1.100 millones de pesos. Laboran en la rama unas 40 mil personas; las capacidades de producción de cemento se elevaron hasta 5.220.000 tone- 
ladas, en 6 fábricas de proceso seco y húmedo. La producción de áridos supera los 12 millones de $\mathrm{m}^{3}$ de piedra y los 5 millones de $\mathrm{m}^{3}$ de arena. Las más de 100 plantas de elementos prefabricados disponen de potencial por encima del millón de $\mathrm{m}^{2}$.

El desarrollo de la effera del transporte incluyó varias direcciones. Así, el transporte ferroviario cuenta con unos $12.600 \mathrm{~km}$, de los cuales 4.800 corresponden al servicio público; electrificado existen unos $155 \mathrm{~km}$. Fue reconstruida la vía central H abana-Santiago de Cuba en 865 km; los desembolsos se acercaron a los 1.300 millones de pesos, incluyendo los correspondientes a obras de infraestructura para el mantenimiento y los talleres auxiliares. El movimiento de carga y pasajeros disponía de unas 400 locomotoras y más de 9 mil vagones para ambos usos, alcanzando topes máximos de transporte de carga del orden de los 18 millones de toneladas, para un 15\% de los volúmenes transportados y movimiento de viajeros por 26 millones.

El transporte automotor contó, ante todo, con una red de autopistas y carreteras asfaltadas que alcanza $15 \mathrm{mil} \mathrm{km}$, aunque se reconoce que un $60 \%$ de esta longitud se clasifica como regular o en mal estado. El parque móvil para fines de los años ochenta superaba las 100 mil unidades, entre camiones y ómnibus; la carga de mercancías rozaba los 75 millones de toneladas, al go más del $70 \%$ del total transportado; el movimiento de pasajeros los 2.800 millones de personas, equivalentes al $92 \%$ de los viajeros.

I gualmente, el sistema portuario recibió entre 1976 y 1990 unos 1.100 millones de pesos en inversiones, lo que posibilitó ampliar, modernizar, construir nuevos muelles y atraques, introducir modernos equipos e instalaciones especializadas para la manipulación de contenedores, descargas de buques cisternas y tanqueros, así como del tipo roll-on/roll off. D e este programa se beneficiaron los puertos de $\mathrm{M}$ ariel, La $\mathrm{H}$ abana, M atanzas, $\mathrm{N}$ uevitas, la bahía de $\mathrm{N}$ ipe, Santiago de Cuba y Cienfuegos. Los trasiegos de carga y descarga llegaron al tope de 45 millones de toneladas de mercancías secas y líquidas, distribuidas en unas 35 de exportación-importación y otros 10 millones de toneladas de cabotaje.

Por otra parte, el país se dotó de modernas flotas marítima y aérea. Para 1989 los buques de la flota mercante sumaban 117 con registro bruto de 929 mil toneladas y peso muerto de 1.400 .000 toneladas, distribuidas en modernos cargueros, naves refrigeradas, portacontenedores, tanqueros, granaleros y otros. A la vez, la flota aérea disponía de 45 aeronaves de diferente porte que cubren 45 rutas internacionales. Además, se emplearon más de 300 millones de pesos en la remodelación y construcción de nuevos aeropuertos e instalaciones auxiliares; disponiéndose de terminales en La H abana, Varadero, Camagüey, H olguín, Santiago de C uba y C ayo Largo del Sur, con categoría de aeropuerto internacional. El movimiento de pasajeros se estabilizó en los años ochenta con al rededor de los 700 mil viajeros anuales.

En las comunicaciones ampliar y modernizar la rama incluyó la automatización del sector telegráfico nacional, al tiempo que el correo se extendió a todos los puntos de la Isla, ofreciendo la atención en 1.046 oficinas postales. 
La red telefónica explota unas 325 mil líneas, lo que hace una densidad de 5 telé fonos por 100 habitantes; estando la telefonía sometida a remodelación en un plazo de 7 años para lograr la total automatización del servicio, así como ele var hasta 20 y 30 teléfonos el índice de densidad del país y en Ciudad de La $\mathrm{H}$ abana, respectivamente. Las comunicaciones vía satélite se realizan por los sistemas Intersputnik e Intersat, utilizando unos 90 canales; e levándose los servicios telefónicos internacionales al establecerse 240 líneas y llevar a 64 los canales externos del servicio de télex.

Por otra parte, la base de las cadenas nacionales de radiodifusión emplean 165 centros transmisores de radio por onda media, con 210 equipos que suman más de $1.800 \mathrm{kV}$ de potencia; funcionan 61 centros que difunden la señal televisiva, que abarca el $90 \%$ de la I sla. En total existen casi 400 transmisores y cerca de 220 campos de anten ${ }^{25}$. Al final del quinquenio quedará instalada la televisión por cable.

Asimismo, parte esencial de la infraestructura material con que cuenta el país, lo constituyen las más de 200 U nidades de Ciencia y T écnica (U CT ), incluidos decenas de centros de investigación especializados y ramales. Por los recursos destinados a investigación y desarrollo Cuba ocupa el primer lugar en América Latina. Baste señalar que sólo entre 1977 y 1989 se destinaron a las actividades científicas unos 500 millones de pesos sin contar los gastos corrientes. Laboran en la red científica nacional 30 mil personas; de ellas, 8.500 con nivel superior y más de 5.300 investigadores ${ }^{26}$. A este potencial se agregan 20 mil profesores universitarios vinculados en parte de su tiempo a las investigaciones, así como los 250 mil graduados universitarios que desarrollan actividades en la producción o los servicios.

$$
* * *
$$

Finalmente, entre 1990 y 1993 la economía de C uba se vio sometida a una profunda crisis. Vale recordar que el $85 \%$ de los vínculos económicos externos estaban estructurados dentro de la comunidad del CAM E. La desaparición del socialismo en Europa del Este y la posterior desintegración de la URSS obligó a un ajuste de los mecanismos económicos internos y al replanteo de la inserción cubana en la economía mundial. Sólo en 1994 con un 0,7\% de crecimiento fue detenida la caída del Producto Interior Bruto, el que había pasado de los 19,6 miles de millones en 1989 a los 12,8 miles de millones de pesos en 1993; y en 1995 se obtenía una elevación del 2,5\% del PIB. Para 1996 el incremento está fijado en un $5 \%$ con un notable auge en las ramas industriales, agropecuaria y la construcción, principalmente en la esfera azucarera, con una recuperación productiva de más del $30 \%$. 